\title{
Correction: Buprenorphine-naloxone practice and attitudes in 22 Canadian emergency physician groups: a cross- sectional survey
}

Errors occurred in an article published Sept. 21, 2021. ${ }^{1}$

The title "A cross-sectional survey on buprenorphinenaloxone practice and attitudes in 22 Canadian emergency physician groups: a cross-sectional survey" should have been "Buprenorphine-naloxone practice and attitudes in 22 Canadian emergency physician groups: a cross-sectional survey."

Also, the author name "Scheueremeyer" should have been "Scheuermeyer" in the author byline, affiliations and contributors statement.

These errors have been corrected at cmajopen.ca.

\section{Reference}

1. Kestler A, Kaczorowski J, Dong K, et al. Buprenorphine-naloxone practice and attitudes in 22 Canadian emergency physician groups: a cross-sectional survey. CMA7 Open 2021;9:E864-73.

CMAJ Open 2021 October 5. DOI:10.9778/cmajo.20210253 